\title{
Completely background free broadband coherent anti-Stokes Raman scattering spectroscopy
}

\author{
Liu, Xing; Niu, Hanben; Liu, Wei; Chen, Danni; Zhou, Binbin; Bache, Morten
}

Published in:

2013 Conference on Lasers \& Electro-Optics Europe \& the International Quantum Electronics Conference (CLEO/Europe-IQEC)

Link to article, DOI:

10.1109/CLEOE-IQEC.2013.6801508

Publication date:

2013

Link back to DTU Orbit

Citation (APA):

Liu, X., Niu, H., Liu, W., Chen, D., Zhou, B., \& Bache, M. (2013). Completely background free broadband coherent anti-Stokes Raman scattering spectroscopy. In 2013 Conference on Lasers \& Electro-Optics Europe \& the International Quantum Electronics Conference (CLEO/Europe-IQEC) IEEE. https://doi.org/10.1109/CLEOEIQEC.2013.6801508

\section{General rights}

Copyright and moral rights for the publications made accessible in the public portal are retained by the authors and/or other copyright owners and it is a condition of accessing publications that users recognise and abide by the legal requirements associated with these rights.

- Users may download and print one copy of any publication from the public portal for the purpose of private study or research.

- You may not further distribute the material or use it for any profit-making activity or commercial gain

- You may freely distribute the URL identifying the publication in the public portal 


\title{
Completely background free broadband coherent anti-Stokes Raman scattering spectroscopy
}

\author{
Xing Liu ${ }^{1,2}$, Hanben $\mathrm{Niu}^{2}$,Wei Liu' ${ }^{2}$,Danni Chen ${ }^{2}$,Binbin Zhou ${ }^{1}$, Morten Bache ${ }^{1}$
}

${ }^{I}$ Technical University of Denmark, DTU Fotonik, Dept. of Photonics Engineering, DK-2800 Kgs. Lyngby, Denmark

${ }^{2}$ Key Laboratory of Optoelectronic Devices and Systems of Ministry of Education and Guangdong Province, Institute of Optoelectronics, Shenzhen University, Shenzhen, Guangdong 518060, China

3-color coherent anti-Stokes Raman scattering (CARS) can be used to measure the dynamics of vibrationally excited states by controlling the time delay between the broadband and narrowband pulses. It is promising to simultaneously obtain the CARS spectra in time-frequency domains and monitor vibration dephasing times of multiple Raman modes, which is especially favourable in the studies of molecular dynamics, supra-molecular structure, chemistry and material science [1].However, the often present instantaneous nonresonant background (NRB) signal interferes with and typically dominates the much weaker resonant signals, leading to significant reduction [2].
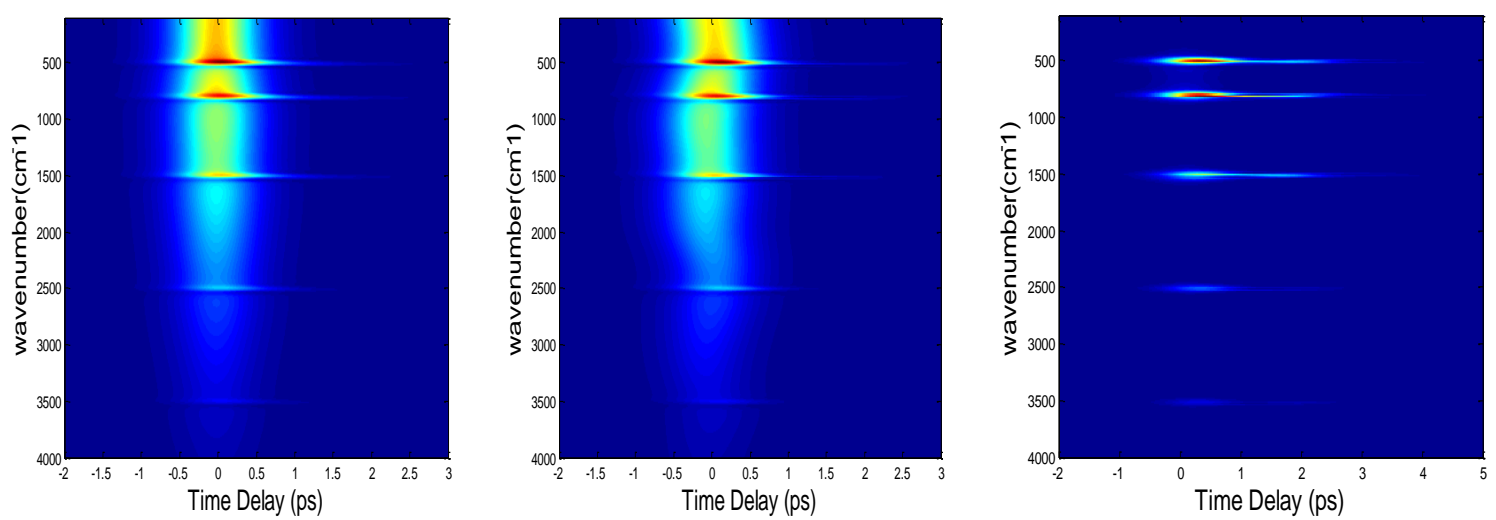

Fig. 1 (a) simulated CARS spectrogram (b) the retrieved CARS spectrogram (C) non-NRB CARS spectrogram

Here we for the first time propose a numerical approach to obtain non-NRB time-frequency CARS spectrograms. In order to evaluate the validity of the CARS spectrogram for background free broadband CARS spectroscopy, we numerically constructed a CARS spectrogram for an assumed Gaussian probe pulse of 500fs (FWHM) according to equation $I_{t-c a r s}\left(\omega_{a s}, \tau\right)=||_{-\infty}^{+\infty}+\infty R(t) E_{p r}(t-\tau) \exp (-i \omega t) \mid(1)$; the time-frequency CARS spectrogram is shown in Fig. 1(a). The molecular time response $R(t)$, includes two parts, namely resonant vibration population decay ( $\mathrm{t}>10 \mathrm{fs}$ ) and a nonresonant background $(\mathrm{t}<10 \mathrm{fs})$. In addition, the time-delay control allows separation of nonresonant background (NRB) contribution from the resonant signal by taking advantage of different time scales of NRB ( $<10 \mathrm{fs}$ ) and vibrational coherence ( $0.5 \mathrm{ps} \sim 10 \mathrm{ps})$. However, time-resolved CARS largely reduces the resonant signal. We can retrieve the $\mathrm{R}(\mathrm{t})$ from the simulated CARS spectrogram, and we implemented an iterative Fourier-transform algorithm with a generalized projection method [3]. By complete separation of the time evolution of the CARS signals and the NRB, we define the step functions $R^{\prime}(\mathrm{t})=\mathrm{R}(\mathrm{t})$ (if $\mathrm{t}>10 \mathrm{fs}$ ), otherwise $R^{\prime}(\mathrm{t})=0$. We numerically constructed a non-NRB CARS according to equation (1), which used the $R^{\prime}(\mathrm{t})$ instead of $\mathrm{R}(\mathrm{t})$. The spectrogram in Fig.1(c) clearly shows that we are able to simultaneously obtain multiple Raman modes (covering $500 \mathrm{~cm}^{-1}$ to $4000 \mathrm{~cm}^{-1}$ ) with no NRB noise in a single measurement both in the time and frequency domain. Concluding we demonstrated a way of removing NRB signal from broadband CARS spectroscopy. Using a numerical approach, the background-free vibrational spectrum can be measured from $500-4000 \mathrm{~cm}^{-1}$ in the time and frequency domain, and significantly increases the detection sensitivity of CARS spectroscopy. This novel simple method should be useful for probing a local chemical identity.

\section{References}

[1] A. Zumbusch, G. R. Holtom, and X. S. Xie, "Three-dimensional vibrational imaging by coherent anti-stokes Raman scattering," Phys. Rev. Lett.82(20), 4142-4145 (1999).

[2] Jun Yin, Ling-Yao Yu, Xing Liu,Wan Hui, Lin Zi-Yang, and Han-Ben Niu, "Simultaneous measurements of global vibrational spectra and dephasing times of molecular vibrational modes by broadband time-resolved coherent anti-Stokes Raman scattering spectrography ," Chin. Phys. 20(1), 014206 (2011) ; Xing Liu, Wei Liu, Jun Yin, Hanben Niu , "Optimization of Supercontinuum Sources for Ultra-Broadband T-CARS Spectroscopy," Chin. Phys. Lett. 28(3), 034202 (2011).

[3] R. Trebino, K. W. DeLong, D. N. Fittinghoff, J. N. Sweetser, M. A. Krumbügel, and D. J. Kane, "Measuring Ultrashort Laser Pulses in the TimeFrequency Domain Using Frequency-Resolved Optical Gating," Review of Scientific Instruments 68, 3277-3295 (1997). 